\title{
PENGARUH GAYA HIDUP, PROMOSI DAN DEMOGRAFI TERHADAP KEPUTUSAN MEMBELI SMARTPHONE BLACKBERRY
}

\author{
Nursinta Harmaniar \\ HIMPSI Provinsi DKI Jakarta
}

\begin{abstract}
This study aims to examine effects of lifestyle, promotion and demography factors on decision to buy blackberry smartphone. This quantitative study using regression analysis with 150 student at faculty of psychology of UIN Syarif Hidayatullah Jakarta as sample. 75 items scales containing 8 items of decision to buy blackberry smartphone, 29 items of lifestyle scale, and 38 items of promotion scale. There was also demography scale with three questions. Result of this study showed that lifestyle, promotion, and demography influenced decision to buy blackberry smartphone significantly. 32.2\% regression coefficient was obtained with $67.8 \%$ residual. There are only two significants independent variables, opinion and promotion.
\end{abstract}

Keywords: decision to buy, lifestyle, promotion, demography

\begin{abstract}
Abstrak
Penelitian ini bertujuan untuk mengetahui seberapa besar pengaruh gaya hidup, promosi dan demografi terhadap keputusan membeli smartphone blackberry. Penelitian kuantitatif dengan analisis regresi melibatkan 150 sampel pada mahasiswa Fakultas Psikologi UIN Syarif Hidayatullah Jakarta tahun akademik 2010/2011 sampai dengan tahun akademik 2012/2013. Sampel penelitian ini terdiri dari 150 responden yang masing - masing subjek diberikan skala dengan jumlah item sebanyak 75 item yang terdiri dari 8 item skala keputusan membeli smartphone blackberry, 29 item skala gaya hidup dan 38 item skala promosi. Skala demografi yang berupa 3 pertanyaan untuk menunjang penelitian. Hasil penelitian menujukkan bahwa gaya hidup, promosi dan demografi berpengaruh signifikan terhadap keputusan membeli smartphone blackberry. Berdasarkan proporsi varian keseluruhan, keputusan membeli smartphone blackberry yang dipengaruhi independent variabel (gaya hidup, promosi dan demografi) memberikan sumbangan sebesar 32.2\%. Sisanya sebesar $67.8 \%$ dapat dipengaruhi oleh faktor lain diluar penelitian ini. Dalam penjabarannya ditemukan hanya dua yang signifikan mempengaruhi keputusan membeli smartphone blackberry secara positif yaitu dimensi opini dan dimensi promosi penjualan. Variabel gaya hidup pada aspek opini memberikan sumbangan $25.4 \%$ dan variabel promosi pada aspek promosi penjualan dengan sumbangan $2.5 \%$.
\end{abstract}

Kata kunci: Keputusan membeli, Gaya hidup, Promosi dan Demografi. 


\section{PENDAHULUAN}

Komunikasi merupakan salah satu kebutuhan bagi mahasiswa sebagai makhluk sosial (Santoso, 2010). Kebutuhan untuk berkomunikasi meningkat karena mahasiswa ingin menyampaikan dan menerima informasi dimana dan kapan saja. Oleh karena itu mahasiswa membutuhkan sebuah alat perantara, yang sekarang lebih akrab dengan sebutan ponsel cerdas (smartphone).

Smartphone yang sedang menguasai pasar di Indonesia pada saat ini ialah blackberry (Sulistyawati, 2011). Produk ini begitu fenomenal karena tidak hanya para pebisnis, 
eksekutif, bahkan ibu rumah tangga dan mahasiswa juga turut menggunakan blackberry. Pada mahasiswa mengambil keputusan membeli smartphone blackberry tentu saja menuntut bersikap pintar, cermat, efisien dan efektif dalam memilih produk yang diinginkan. Dengan adanya sikap itu, maka mahasiswa tidak akan kecewa dengan apa yang telah mereka beli.

Namun berdasarkan pengamatan, keputusan membeli pada mahasiswa juga dipengaruhi oleh gaya hidup. Besar kecilnya perubahan yang terjadi pada gaya hidup mahasiswa tergantung dari seberapa kuat tuntutan zaman mempengaruhinya (Lusprentry, 2009). Setiap individu memiliki latar belakang dan karakteristik yang berbeda-beda. Perbedaan ini dapat dilihat dari aktivitas, minat dan pendapat mahasiswa yang tercermin dari pola perilaku mereka sehari-hari yang berbeda antara satu individu dengan individu lainnya.

Aktivitas di mana mahasiswa melakukan kegiatan dalam memenuhi kebutuhannya seperti berkomunitas, belanja, hiburan, dan olahraga. Minat mahasiswa juga didasari keinginan terhadap produk yang diinginkan. Pendapat mahasiswa terhadap produk yang akan dibeli sehingga dapat mempengaruhi perilaku keputusan membeli(Engel, Blackwell \& Miniard, 1995:383). Oleh karena itu setiap mahasiswa mempunyai kemampuan yang berbeda-beda dalam mengambil keputusan membeli.

Faktor demografi juga mempengaruhi gaya hidup pada mahasiswa. Demografi adalah sebagai suatu populasi yang didasarkan pada jumlah masyarakat yang ada di suatu masyarakat, struktur masyarakat (meliputi jenis kelamin, penghasilan, pendidikan dan pedapatan), dan distribusi, yaitu lokasi fisik secara geografis (Hawkins, Best \& Coney, 1995). Oleh karena itu, demografi menjadi penguatan dari proses gaya hidup. Hal ini sangat berhubungan dengan pengambilan keputusan dalam pembelian yang dilakukan oleh mahasiswa.

Saat ini banyaknya mahasiswa yang menggunakan Blackberry ke kampus karena salah satu gaya hidupnya. Misalnya fenomena yang saat ini terjadi banyaknya konsumen khususnya mahasiswa mengeluarkan bugdet yang tidak sedikit untuk membeli Blackberry, karena dengan fitur-fitur yang terdapat di dalam Blackberry akan dapat mendukung proses pemenuhan gaya hidup mahasiswa. Mahasiswa sebagai generasi muda yang suka mengikuti tren dimanfaatkan produsen smartphone Blackberry yang dengan gencar meluncurkan produk-produk baru berteknologi tinggi (Mahedro, 2011). Dengan semakin banyaknya jenis smartphone yang ada, maka perusahaan smartphone Blackberry turut bersaing dalam menciptakan sebuah inovasi baru yang dapat memberikan kepuasan bagi pemakai smartphone itu sendiri baik dari segi pengoperasiannya, kualitasnya, desainnya dan kelengkapan menunya sehingga dengan demikian konsumen dapat menentukan pilihannya. Untuk dapat menjalankan semua itu, maka perusahaan dituntut menetapkan promosi yang tepat dan terarah dalam menempatkan produknya dibenak konsumen, sehingga konsumen akan mampu membedakan produknya bila dibandingkan dengan produk dari perusahaan lain.

Promosi juga termasuk faktor yang paling penting dalam menentukan sebuah pengambilan keputusan membeli. Ada empat jenis promosi yang utama mempengaruhi, seperti : iklan, promosi penjualan, penjualan personal dan publisitas (Nickels dkk, 2010). Namun dalam penelitian ini dimodifikasi hanya aspek iklan dan promosi penjualan saja. 
Iklan berperan sebagai penyajian penjualan non-personal yang dikomunikasikan melalui bentuk media atau non-media untuk mempengaruhi sejumlah besar mahasiswa. Promosi penjualan (sales promotion) juga berperan sebagai menarik perhatian mahasiswa dan memberikan informasi yang mengarah pada pembeliaan. Semuanya memberikan insentif kuat untuk membeli dengan menyediakan dorongan atau kontribusi yang memberikan nilai tambah bagi mahasiswa. Dorongan yang dimaksud seperti kupon, perlombaan, pemotongan harga, dan hadiah (Kotler, 2008:266). Dengan demikian promosi diharapkan membuat mahasiswa melakukan keputusan membeli akan produk yang ditawarkan, yaitu Smartphone Blackberry.

Berdasarkan hal tersebut, maka penelitian ini bertujuan untuk mengetahui pengaruh gaya hidup dan promosi terhadap proses pengambilan keputusan pembelian khususnya pada mahasiswa Fakultas Psikologi Universitas Islam Negeri Syarif Hidayatullah Jakarta tahun akademik 2010/2011 sampai dengan tahun akademik 2012/2013.

\section{HIPOTESIS}

Berdasarkan kerangka berpikir yang ada, dapatlah dirumuskan hipotesis sebagai berikut:

\section{Major :}

Apakah terdapat pengaruh yang signifikan antara gaya hidup, promosi dan demografi terhadap keputusan membeli Smartphone Blackberry?

\section{Minor :}

1. Apakah terdapat pengaruh yang signifikan aktivitas (activities) dalam variabel gaya hidup terhadap keputusan membeli Smartphone Blackberry?

2. Apakah terdapat pengaruh yang signifikan minat (interest) dalam variabel gaya hidup terhadap keputusan membeli Smartphone Blackberry?

3. Apakah terdapat pengaruh yang signifikan opini (opinion) dalam variabel gaya hidup terhadap keputusan membeli Smartphone Blackberry?

4. Apakah terdapat pengaruh yang signifikan periklanan dalam variabel promosi terhadap keputusan membeli Smartphone Blackberry?

5. Apakah terdapat pengaruh yang signifikan promosi penjualan dalam variabel promosi terhadap keputusan membeli Smartphone Blackberry?

6. Apakah terdapat pengaruh yang signifikan jenis kelamin dalam variabel demografi terhadap keputusan membeli Smartphone Blackberry?

7. Apakah terdapat pengaruh yang signifikan pendapatan orang tua dalam variabel demografi terhadap keputusan membeli Smartphone Blackberry?

8. Apakah terdapat pengaruh yang signifikan penghasilan mahasiswa dalam variabel demografi terhadap keputusan membeli Smartphone Blackberry? 


\section{METODE PENELITIAN}

Metode penelitian ini adalah Explanatory Research, yaitu penelitian yang bermaksud menjelaskan pengaruh antara gaya hidup, promosi dan demografi terhadap keputusan membeli Smartphone blackberry. Teknik yang digunakan dalam penelitian ini adalah nonprobability sampling. Dengan teknik pengambilan sampel menggunakan accidental sampling. Karena subjek penelitian ini yang kebetulan dijumpai atau dapat dijumpai, yaitu mahasiswa.

Populasi dalam penelitian ini adalah mahasiswa Fakultas Psikologi Universitas Islam Negeri Syarif Hidayatullah Jakarta tahun akademik 2010/2011 sampai tahun akademik 2012/2013 yang membeli dan menggunakan Smartphone Blackberry sebanyak 308 responden. Sampel yang diambil dalam penelitian ini menggunakan rumus Slovin, dalam Sevilla, et.al (2006:161). Sebagai berikut:

$$
\mathfrak{n}=\frac{N}{1+N e^{2}}
$$

\section{Keterangan :}

$\eta$ : Ukuran Sampel

$\mathrm{N}$ : Ukuran populasi

e : Nilai kritis (batas ketelitian) yang diinginkan (persen kelonggaran ketidaktelitian karena kesalahan pengambilan sampel populasi), yaitu $6 \%$

Jika tingkat kesalahan yang diinginkan (e) adalah $6 \%$ dan ukuran populasi $(\mathrm{N})=$ 308 , maka jumlah sampel yang diteliti adalah sebanyak:

$$
\begin{gathered}
\mathfrak{n}=\frac{N}{1+N e^{2}} \\
\mathfrak{n}=\frac{308}{1+308(0,06)^{2}} \\
\mathfrak{n}=\frac{308}{1+308(0,0036)} \\
\mathfrak{n}=\frac{308}{2,108}
\end{gathered}
$$

$\mathfrak{n}=146$

Dari perhitungan di atas, maka dapat diketahui bahwa jumlah sampel yang digunakan dalam penelitian ini sebanyak 146 responden.

\section{KESIMPULAN}

Berdasarkan hasil analisis data penelitian maka kesimpulan yang dapat diambil dari penelitian ini adalah: "terdapat pengaruh yang signifikan dari gaya hidup, promosi dan demografi terhadap keputusan membeli smartphone blackberry". 
1. Berdasarkan proporsi varian seluruhnya, keputusan membeli smartphone blackberry yang dipengaruhi independent variabel (gaya hidup, promosi dan aspek demografi) adalah sebesar $32.2 \%$. Sisanya sebesar $67.8 \%$ dapat dipengaruhi oleh faktor lain diluar penelitian ini.

2. Delapan variabel yang diuji hanya dua variabel independen saja yang dinyatakan signifikan dan mempengaruhi keputusan membeli smartphone blackberry, yaitu: aspek opini dan promosi penjualan.

3. Kemudian jika dilihat berdasarkan sumbangan dari masing-masing IV yang diteliti termasuk IV kategori dapat diambil kesimpulan, ternyata terdapat dua variabel yang signifikan sumbangannya. Variabel-variabel tersebut antara lain adalah gaya hidup pada aspek opini dengan sumbangan $25.4 \%$ dan promosi pada aspek promosi penjualan dengan sumbangan $2.5 \%$.

\section{Diskusi}

Berdasarkan hasil pengujian hipotesis pengaruh gaya hidup dan promosi terhadap keputusan membeli smartphone blackberry yang dilakukan peneliti menunjukkan bahwa ada pengaruh yang signifikan dari seluruh independent variabel terhadap keputusan membeli smartphone blackberry. Berdasarkan proporsi varians seluruhnya, keputusan membeli smartphone blackberry yang dipengaruhi independent variabel (promosi, gaya hidup dan aspek demografi) adalah sebesar 32.2\%. Hasil ini sejalan dengan teori yang dinyatakan oleh Hawkins, Best \& Coney (1995) bahwa keputusan membeli dipengaruhi oleh faktor internal dan faktor eksternal. Faktor internal yang didalamnya terdapat gaya hidup, sedangkan faktor eksternal menjelaskan demografi dan aktivitas marketing yang didalamnya terdapat promosi.

Sesuai dengan nilai signifikansi sebesar 0.000 dan dengan nilai kontribusi variabel independent variable (IV) terhadap dependent variabel (DV) sebesar 0.322 atau $32.2 \%$, dimana artinya bahwa gaya hidup, promosi dan aspek demografi memiliki pengaruh terhadap keputusan membeli smartphone blackberry sebesar $32.2 \%$ dan sisanya sebesar $67.8 \%$ dapat dipengaruhi oleh faktor lain diluar penelitian ini. Faktor-faktor tersebut terdapat dalam teori Hawkins, Best, Coney (1995), yaitu : faktor yang berasal dari lingkungan seperti budaya, sub budaya, status sosial, kelompok acuan, dan keluarga dapat mempengaruhi proses pengambilan keputusan seseorang. Adapun beberapa hal yang bersifat individual yang dapat mempengaruhi yaitu persepsi, belajar, memori, motivasi, kepribadian, sikap, dan konsep diri. Faktor - faktor ini yang memiliki peluang mempengaruhi keputusan membeli selain gaya hidup, promosi dan aspek demografi.

Jika dilihat dari variabel gaya hidup secara utuh terdapat pengaruh yang signifikan terhadap keputusan membeli smartphone blackberry. Hasil ini sejalan dengan penelitian sebelumnya yang dilakukan oleh Suwanvijit (2009), mengindikasikan bahwa gaya hidup dapat mempengaruhi pengambilan keputusan, sadar ekonomi, dan kenyamanan konsumen. Secara statistik, ada signifikan antara karakteristik sosioekonomi, demografi, dan gaya hidup terhadap perilaku membeli. 
Sedangkan menurut Swasti Dian Pratiwi menemukan bahwa dimensi Activity, Interest dan Opinion (AIO) berpengaruh positif terhadap keputusan pembelian produk baju Muslim pada batik Shafira. Yang artinya setiap kenaikan ketiga variabel tersebut akan menaikkan keputusan pembelian konsumen. Dalam studinya, opini (opinion) juga berpengaruh positif terhadap keputusan pembelian, sehingga dapat disimpulkan bahwa pandangan umum yang sangat mempengaruhi keputusan pembelian busana muslim Shafira.

Jika dilihat dari nilai koefisien regresi opini (opinion) sebesar 0.336 dengan signifikansi 0.008 ( $\mathrm{p}<0.05)$, menunjukkan variabel opini (opinion) secara positif mempengaruhi keputusan membeli smartphone blackberry dan signifikan. Uji regresi masing-masing IV pun terungkap bahwa opini (opinion) memiliki nilai $\mathrm{R}^{2}$ change sebesar 0.254 yang artinya $25.4 \%$ varians dari keputusan membeli dipengaruhi oleh opini (opinion). Jadi semakin tinggi opini (opinion) maka semakin tinggi keputusan membeli smartphone blackberry.

Menurut Engel, Blackwell \& Miniard (1995), Dimensi opini merupakan jawaban lisan atau berupa tulisan yang diberikan oleh seseorang terhadap stimulus berupa pertanyaan. Opini ini digunakan untuk menjelaskan interpretasi, harapan, dan evaluasi seperti beliefs atau keyakinan yang dimiliki oleh seseorang. Opini merupakan pendapat, keyakinan atau pemahaman seseorang mengenai sesuatu yang mereka amati melalui indera yang mereka miliki. Dengan demikian, tingginya nilai opini pada penelitian ini menggambarkan betapa pentingnya pengaruh opini yang dimiliki publik terhadap perkembangan dan pemasaran suatu produk. Jika dilihat dari hasil penelitian ini, maka tingginya opini publik akan berpengaruh besar terhadap perkembangan dan pemasaran suatu merek, karena tujuan pemasaran adalah penjualan, dan penelitian ini menggambarkan tingginya opini akan berpengaruh besar terhadap keputusan publik untuk membeli suatu merek atau produk.

Kemudian jika dilihat dari variabel promosi secara utuh terdapat pengaruh yang signifikan terhadap keputusan membeli smartphone blackberry. Hasil ini sejalan dengan penelitian sebelumnya yang dilakukan oleh Masfuana menyatakan bahwa variabel promosi mempunyai pengaruh positif dan signifikan terhadap variabel keputusan pembelian sehingga hipotesis diterima. Sedangkan penelitian yang dilakukan oleh Jamaludin Al Afghani (2010) juga mengungkapkan bahwa promosi penjualan memberikan pengaruh $11.6 \%$ terhadap keputusan pembelian CDMA Esia. Hal ini dibuktikan dengan nilai signifikansi sebesar 0.018 yang lebih kecil dari $\mathrm{p}<0.05$.

Jika dilihat dari nilai koefisien regresi promosi penjualan sebesar 0.269 dengan signifikansi $0.027(\mathrm{p}<0.05)$, artinya variabel promosi pada aspek promosi penjualan (sales promotion) secara positif berpengaruh terhadap keputusan membeli smartphone blackberry dan signifikan. Uji regresi masing-masing IV pun terungkap bahwa promosi penjualan memiliki nilai $\mathrm{R}^{2}$ change sebesar 0.025 yang artinya $2.5 \%$ varians dari keputusan membeli dipengaruhi oleh promosi penjualan. Jadi semakin 
tinggi promosi penjualan maka semakin tinggi keputusan membeli smartphone blackberry.

Menurut Nickels dkk (2010), promosi penjualan adalah alat promosi yang menstimulasi pembelian dan minat konsumen melalui aktivitas-aktivitas jangka pendek. Aktivitas ini erat kaitannya dalam hal promosi yang bersifat persuasive. Dalam bentuk potongan harga (diskon), memberikan hadiah, display (pemajangan), dan event-event khusus sangat efektif mempengaruhi keputusan membeli smartphone blackberry.

Dalam penelitian ini, terhadap dimensi periklanan dalam variabel promosi yang memperoleh $\mathrm{R}^{2}$ change sebesar 0.000 . Artinya tidak memberikan sumbangan terhadap keputusan membeli smartphone blackberry. Hal ini diperkirakan karena kurangnya mahasiswa mendapatkan informasi atau pesan tentang produk smartphone blackberry melalui periklanan. Produsen blackberry juga yang kurang gencar mempromosikan blackberry melalui periklanan karena biaya yang mahal. Sesuai dengan teori Nickels dkk (2010:189), Iklan (advertising) adalah komunikasi non-personal dengan bayaran melalui berbagai media oleh organisasi-organisasi dan individu-individu yang dengan satu cara teridentifikasi di dalam pesan.

Dalam penelitian ini peneliti melakukan kesalahan dalam pembagian angket yang kurang proposional dan tidak ada keseimbangan jumlah responden berdasarkan jenis kelamin. Peneliti menggunakan teknik pengambilan sampel accidental sampling pada pembeli dan pengguna Smartphone blackberry, seharusnya menggunakan teknik pengambilan sampel simple random sampling. Karena responden sudah bersifat homogen yaitu pembeli dan pengguna smartphone blackberry.

\section{Saran}

Berdasarkan penulisan penelitian ini, peneliti menyadari bahwa masih terdapat banyak kekurangan/keterbatasan dalam penelitian ini.

\section{Saran Teoritis}

1. Pada penelitian selanjutnya, disarankan untuk melakukan ragam dalam karakteristik sampel penelitian yang tidak hanya ditujukan kepada mahasiswa fakultas psikologi UIN syarif Hidayatullah Jakarta saja namun bisa mahasiswa fakultas/universitas lain ataupun masyarakat. Sehingga hasil penelitian menjadi lebih kaya.

2. Pada penelitian selanjutnya, disarankan variabel lain yang dapat diprediksi untuk menggambarkan keputusan membeli dapat berupa persepsi, motivasi, citra merek dan pola asuh orang tua.

3. Untuk menghindari kesalahpahaman dalam menjawab pertanyaan pada kuesioner maka peneliti diharapkan bisa langsung turun lapangan untuk menghindari bias atau ketidaksesuaian responden dalam mengisi kuesioner sehingga jawaban responden merata. 
4. Untuk penelitian selanjutnya yang serupa, disarankan agar lebih memperhatikan item-item pernyataan pada skala, baik dari segi kuantitas maupun kualitas pernyataan agar lebih mengukur apa yang ingin diukur.

5. Untuk penelitian selanjutnya jika ingin menggunakan dependent variable (keputusan membeli) disarankan melakukan logistic regression agar hasil penelitian bisa lebih baik.

6. Penelitian selanjutnya diharapkan tidak hanya mengukur pada produk smartphone blackberry saja, tetapi bisa dengan produk android, tablet, i-pad dan lain - lain.

\section{Saran Praktis}

Dalam melaksanakan pengambilan keputusan membeli, hendaknya konsumen selalu bersikap rasional sehingga apa yang dibelinya benar -benar dapat memuaskan kebutuhan dan lebih berguna untuk memenuhi kebutuhan hidup sehari-hari khususnya penggunaan smartphone blackberry. Bagi perusahaan yang mempromosikan produknya, sebaiknya tidak hanya menonjolkan sisi emosional tetapi juga harus memberikan aspek rasional dan muatan edukatif serta selalu memberikan pelayanan dalam kualitas produk. Sehingga konsumen secara rasional dapat mengetahui untuk apa mereka membeli dan apa manfaat serta kepuasan yang akan mereka dapatkan. Khususnya konsumen smartphone blackberry yang harus mengetahui manfaat dan kebutuhan yang didapat dari smartphone blackberry. 


\section{DAFTAR PUSTAKA}

Afghani, Jamaludin Al. (2010). Analisis pengaruh promosi, penetapan harga, dan ekuitas merek terhadap keputusan pembelian produk telekomunikasi CDMA esia. Jakarta : UIN Syarif Hidayatullah.

Anisa, Mugni. (2012). Faktor demografi. Artikel ini diakses pada tanggal 5 agustus 2013 dari http://anisamugni.wordpress.com/2012/12/03/ faktor-demografi/.

Assael, Henry. (1998). Consumer behavior and marketing action. $6^{\text {th }}$ Edition. New York : South Western College Publishing.

Basu, Swastha. DH. (1999). Saluran pemasaran. yogyakarta : BPFE.

Dianto, Rachman. (2010). Perilaku konsumen dalam pengambilan keputusan terhadap produk yang diinginkan. Artikel ini diakses pada tanggal 5 agustus 2013 dari http://iyano.wordpress.com/2010/11/30/perilaku-konsumen-dalampengambilan-keputusan-terhadap-produk-yang-diinginkan/

Engel, J.F., Blackwell, R.D. \& Miniard, P.W. (1995). Perilaku konsumen, jilid 1. (Terjemahan). Tangerang : Binarupa Aksara Publisher.

Engel, J.F., Blackwell, R.D. \& Miniard, P.W. (1995). Consumer behavior eighth edition. America : The Dryden Press.

Eka, Putridinawati. 2013. Berbagai kelemahan blackberry. Artikel ini diakses pada tanggal 4 Juli 2013 dari Error! Hyperlink reference not valid.1

Fandy, Tjiptono. (2004). Pemasaran jasa. Malang : Bayu Media.

Fred, Kerlinger. (2004). Asas-asas penelitian behavioral. Yogyakarta : Gajah Mada University Press.

Hawkins, Best \& Coney. (1995). Consumer behavior : implication for marketing strategies. Boston: Richard Darwin, Inc.

Joseph T. Plummer, "The concept and application of life style segmentation," Journal of Marketing 38 (Januari 1974), 34. Dicetak ulang dari Journal of Marketing yang diterbitkan oleh American Marketing Association.

Kotler, Philip. (1987). Dasar - dasar pemasaran. edisi ketiga, Jilid 2 (terjemahan). Jakarta : Intermedia.

Kotrler, Philip. (2008). Manajemen pemasaran. Edisi kedua belas, Jilid 2. Jakarta: PT. Indeks.

Kotler, Philip. \& Gary Armstrong. (1997). Dasar-dasar pemasaran, Edisi Bahasa Indonesia. Jakarta : Prenhallindo.

Kotler, Philip. \& Gary Armstrong. (2008). Prinsip-prinsip pemasaran. Edisi Keduabelas. Jilid 1. Jakarta : Erlangga.

Kotler, Philip. \& Gary Armstrong. (2008). Prinsip-Prinsip Pemasaran. Edisi Keduabelas. Jilid 2. Jakarta : Erlangga. 
Lusprentry, Dwinita. (2009). Hubungan gaya hidup dengan keputusan membeli laptop pada mahasiswa UIN syarif hidayatullah jakarta. Jakarta : UIN Syarif Hidayatullah.

Madura, Jeff. (2001). Pengantar bisnis, edisi pertama (terjemahan). Jakarta : Salemba Empat.

Mahendro, AM Anggoro Bayu. (2011). Analisis pengaruh gaya hidup terhadap keputusan pembelian handphone blackberry di kalangan mahasiswa atma jaya. Thesis Fakultas Ekonomi Unika Atma Jaya. Jakarta.

Mowen, C. J. \& Minor, Michael. (2002). Perilaku konsumen, Edisi kelima (terjemahan). Jakarta : Erlangga.

Nickels, W.G., McHugh, J.M. \& McHugh, S.M. (2010). Pengantar bisnis, edisi delapan (terjemahan). Jakarta : Salemba Empat.

Peter, J.P., \& Olson, J.C. (2000). Consumer behavior; perilaku konsumen dan strategi pemasaran, Edisi keempat (terjemahan), Jilid 2. Jakarta : Erlangga.

Prajapati, Prof. Sandup and Prof. Mital Thakor. (2012). Competitive and innovative promotional tools used by toothpaste companies for rural market \& it's impact on consumer buying behaviour in gujarat. Journal of Arts, Science \& Commerce.

Pratiwi, Swasti Dian. Pengaruh dimensi activity, interest, dan opinion (AIO) terhadap keputusan pembelian pada butik busana muslim shafira di samarinda. Samarinda : Fakultas Ekonomi Universitas Mulawarman.

Santoso, Urip. (2010). Komunikasi dalam kehidupan sehari-hari. Artikel ini diakses pada tanggal 5 juni 2013 dari http://uripsantoso.wordpress.com /2010/02/14/komunikasi-dalam-kehidupan-sehari-hari.html.

Schiffman, Leon G. dan Leslie Lazar Kanuk. (1994). Consumer behavior. Fifth Edition. New Jersey : Prentice-Hall International, Inc.

Schiffman, Leon G. dan Leslie Lazar Kanuk. (2000). Consumer behavior. Seventh Edition. London : Prentice-Hall International (UK) Limited.

Schiffman, Leon G. dan Leslie Lazar Kanuk. (2004). Consumer behavior. Eighth Edition. New Jersey : Pearson Education, Inc., Upper Saddle River.

Setiadi, Nugroho J. (2010). Perilaku konsumen: perspektif kontemporer pada motif, tujuan, dan keinginan konsumen. Edisi Revisi, Cetakan ke-4. Jakarta : Kencana.

Setiawan, Fachri. (2013). Definisi demografi menurut para ahli. Artikel ini diakses pada tanggal 15 Mei 2013 dari http://fachri-setiawan.blogspot.com/2013/02/definisidemografi-menurut-para-ahli.html.

Sevilla, Consuelo G. (2006). Pengantar metode penelitian. Jakarta: Universitas Indonesia.

Solomon, Michael R. (2007). Consumer behavior: buying, having, and being. Pearson Education International. 
Stanton, William J. (1967). Fundamentals of marketing. America : McGraw-Hill Book Company.

Sulistyawati, Vivi. (2011). Analisis atribut produk yang dipertimbangkan konsumen dalam pembelian blackberry. Skripsi Universitas Pembangunan Nasional (UPN).

Suwanvijit, Wassana. (2009). The insight study of consumer life-styles and purchasing behaviors in songkla province, Thailand. Internasional Journal of Marketing Studies.

Triastuti, Masfuana. Pengaruh kualitas produk dan promosi terhadap keputusan pembelian yamaha mio (Studi Pada Harpindo Jaya Rembang).

Umar, Jahja Ph.D. (2012). Uji Validitas Konstruk General Aptitude Test Battery (GATB) dengan Metode Confirmatory Factor Analysis (CFA). Jurnal Pengukuran Psikologi dan Pendidikan Indonesia, Vol I, No. 1.

Wiek, (2009). Pengguna blackberry tumbuh pesat. Artikel ini diakses pada tanggal 12 februari 2013 dari http://tekno.kompas.com/read/2009/01/21/ 21371459/Pengguna.BlackBerry. Tumbuh.Pesat. 